\title{
Never in mitosis gene A-related kinase 6 and aurora kinase A: New gene biomarkers in the conversion from ulcerative colitis to colorectal cancer
}

\author{
EMRE GERÇEKER $^{1}$, SEDA ORENAY BOYACIOGLU ${ }^{2}$, ELMAS KASAP $^{1}$, AHMED BAYKAN $^{1}$, HAKAN YUCEYAR $^{1}$, \\ HATICE YILDIRIM $^{2}$, SEMIN AYHAN ${ }^{3}$, ENDER ELLIDOKUZ $^{1}$ and MEHMET KORKMAZ ${ }^{2}$ \\ Departments of ${ }^{1}$ Gastroenterology, ${ }^{2}$ Medical Genetics and Medical Biology, and ${ }^{3}$ Pathology, \\ Medical Faculty, Celal Bayar University, Manisa, Turkey
}

Received May 28, 2015; Accepted July 3, 2015

DOI: $10.3892 /$ or.2015.4187

\begin{abstract}
Ulcerative colitis (UC) is an important risk factor for colorectal cancer (CRC). Histone modifications are one of the epigenetic mechanisms that may have key roles in the carcinogenesis of CRC. At present, there are no studies comparing histone modification patterns of UC and CRC in the literature. Therefore the aim of the present study was to investigate whether genes, particularly those involved in histone modification, have value in patient monitoring with regards to CRC development in UC. Key gene expressions of the histone modification enzyme were assessed and compared in CRC, UC and control groups using the RT-PCR array technique. Patients were divided into subgroups based on the extent and duration of the disease and inflammatory burden, which are considered risk factors for CRC development in UC patients. In UC and CRC groups, a significantly higher overexpression of the NEK6 and AURKA genes compared to the control group was identified. In addition, there was a significantly higher overexpression of $H D A C l$ and $P A K 1$ genes in the UC group, and of $H D A C 1, H D A C 7, P A K 1$ and $A U R K B$ genes in the CRC group. NEK6, AURKA, HDAC1 and PAK1 were significantly overexpressed in patients with a longer UC duration. Overexpression of AURKA and NEK6 genes was significantly more pronounced in UC patients with more extensive colon
\end{abstract}

Correspondence to: Dr Emre Gerçeker, Department of Gastroenterology, Medical Faculty, Celal Bayar University, 173 Mimarsinan Bulv. Manisa, Turkey

E-mail: dr.emre.gerceker@gmail.com

Abbreviations: AURKA, aurora kinase A; AURKB, aurora kinase B; $\mathrm{CRC}$, colorectal adenocarcinoma; HDAC1, histone deacetylase 1; HDAC7, histone deacetylase 7; NEK6, never in mitosis gene A-related kinase 6; PAK1, p-21 activated kinase; UC, ulcerative colitis

Key words: colorectal cancer, ulcerative colitis, epigenetic, histone modifications, never in mitosis gene A-related kinase 6, aurora kinase A involvement. HDAC1, HDAC7, PAK1, NEK6, AURKA and AURKB are important diagnostic and prognostic markers involved in the carcinogenesis of CRC. HDAC1, PAK1, NEK6 and AURKA may be considered as diagnostic markers to be used in CRC screening for UC patients.

\section{Introduction}

Colorectal cancer (CRC) is a well-known complication of ulcerative colitis (UC) and is associated with significant mortality and morbidity. In UC, CRC has an incidence of $0.4 \%$ and a prevalence of $3.5 \%$. CRC accounts for $15 \%$ of mortalities in UC patients $(1,2)$. The risk of developing CRC in UC increases proportionally to the disease duration, early onset, the extent of disease involvement, increased inflammatory burden and presence of primary sclerosing cholangitis (3-6). The occurrence of UC-associated CRC differs from that of sporadic CRC. UC-associated CRC develops from the mucosa with focal or multifocal dysplasia in the presence of inflammation rather than the adenomas and follows the sequence of inflammation-dysplasia-carcinoma $(7,8)$. Several pathways of tumorigenesis and progression including chromosomal instability and microsatellite instability pathways, the $\beta$-catenin/Wnt intermediary pathway, TGF $\beta /$ SMAD intermediary pathway, and RAF/RAS/MAPK intermediary pathway have been described in CRC carcinogenesis. Each of these pathways involves gradual cumulating of multiple mutations that differentiates the pathogenic mechanism. Genetic alternations such as Ki-RAS and B-RAF mutations, 18q deletion, APC and p53 mutations as well as genetic and epigenetic alternations such as DNA CpG islet hypermethylation, non-coding RNA (miRNA) expression and specific histone modifications are observed in many genes involved in these pathways $(7,9,10)$. Epigenetic changes, such as histone modifications, that result in subsequent aberrant gene expression are known to have key roles as ultimate predictors in inflammation-induced colorectal carcinogenesis. Previous findings suggest that histone modification genes including NEK6, AURKA, PAK1, HDAC1, HDAC2, HDAC3, HDAC5 and $H D A C 7$ have key roles in colorectal carcinogenesis (11-19).

There is a need for more effective markers to identify patients who are at a higher risk of developing cancer in order 
to improve CRC screening efficacy and provide more selective treatment strategies in UC patients. At present, there are no studies comparing epigenetic chromatin histone modification patterns of UC and CRC in the literature. We therefore aimed in the present study to investigate whether genes, particularly involved in chromatin histone modification, have value in patient monitoring with regards to CRC development in UC.

\section{Materials and methods}

Study location. The study was performed at the Departments of Gastroenterology and Medical Biology of Manisa Celal Bayar University between July, 2012 and November, 2013. Patients presenting to the Department of Gastroenterology, Manisa Celal Bayar University, were included in the present study.

Ethics committee. The present study was performed in accordance with the declaration of Helsinki, good clinical practice and applicable regulatory requirements. The study was carried out with the approval of the Institutional Ethics Review Board of the Celal Bayar University Medical Center with the approval number 200 dated 26/06/2012. Informed written consent was obtained from each patient.

Study design and samples. Fresh matched tissue samples were collected from a total of 60 patients presenting at the Department of Gastroenterology, Celal Bayar University, between July, 2012 and November, 2013 [group 1 (20 patients) was classified as the macroscopically and histopathologically confirmed CRC group], [group 2 (20 patients) was classified as the macroscopically and histopathologically confirmed UC group], and [group 3 (20 patients) was the control group and included patients with normal colon mucosa with no macroscopically and histopathologically confirmed UC or CRC]. Patients who had received chemotherapy or radiotherapy at any time for any types of cancer, patients diagnosed with any malignancies other than $\mathrm{CRC}$, and patients who received colectomy for any reason, were excluded from the study. Age, gender and history/family history were questioned and documented for all the patients. The extent of colonic involvement of the disease, duration of the disease, activation severity, evidence of extraintestinal involvement, routine evaluations and examinations, results of pathological assessments and drugs used in UC treatment were documented for data purposes in the UC group. For all the patients diagnosed with $\mathrm{CRC}, \mathrm{CT}$ or PET/CT was performed for staging purposes.

Colonoscopy. Colonoscopic examinations of all the patients were performed at the Department of Gastroenterology, Celal Bayar University by the five gastroenterologists (E.K., H.Y., E.E.,E.G. and A.B.) who conducted the study using an Olympus Luxera CFQ260AL colonoscopy unit. Complete colonoscopic examination including the terminal ileum was performed for controls and UC patients. In patients with CRC, ileocolonoscopic examination was completed to determine whether the tumor obliterated the passage access. In CRC patients in whom access to the proximal of the tumor could not be made, proximal of the tumor was assessed using abdominal CT.

For histopathologic and genetic (histone modification gene expression analyses) assessments, mucosal biopsy samples were collected from the tumor tissue in the CRC group, from rectal mucosa with active inflammation in the UC group, and from rectal, cecal and terminal ileal mucosa in the control group with the Olympus biopsy forceps. Pathologic assessments of all the biopsy samples were performed in the Department of Pathology, Celal Bayar University, and the resulting data were documented.

The tissue samples were immediately frozen using dry ice (a block of dry ice has a surface temperature of $-78.5^{\circ} \mathrm{C}$ ) and stored at $-80^{\circ} \mathrm{C}$ until RNA extraction.

RNA isolation from tissue. RNA was isolated using an RNeasy mini kit (Qiagen, Germany) according to the manufacturer's instructions with small modifications. Tissue samples (20-30 mg) from patients, $600 \mu \mathrm{l}$ buffer RLT, and a metal ball with a $7 \mathrm{~mm}$ diameter were homogenized in TissueLyser II homogenizer (Qiagen) at $25,000 \mathrm{~Hz}$ for $5 \mathrm{~min}$. The lysate was centrifuged at maximum speed and the supernatant was treated after this point following the RNeasy mini kit protocol.

Quantity and purity of total RNA. RNA was quantified measuring the absorbance at $260 \mathrm{~nm}$ (A260) and RNA purity was determined by the ratio A260/A280 using a spectrophotometer. RNA quality was considered to be acceptable with A260/A280 at ratio slightly $>2.0$ and A260/A230 ratio at slightly $>1.8$.

cDNA synthesis. The cDNA synthesis was performed using an RT First Strand kit (C-03) (SABiosciences, Frederick, MD, USA). RNA sample ( $8 \mu \mathrm{l})$ was incubated with $2 \mu \mathrm{l}$ of GE (5X gDNA elimination buffer) at $42^{\circ} \mathrm{C}$ for $5 \mathrm{~min}$ in a $0.2 \mathrm{ml}$ PCR tube. In another tube a PCR cocktail [4 $\mu$ l BC3 (5X RT buffer 3), $1 \mu 1 \mathrm{P} 2$ (primer and external control mix), $2 \mu \mathrm{l} \mathrm{RE3}$ (RT enzyme mix 3)], and $3 \mu \mathrm{l} \mathrm{H}_{2} \mathrm{O}$ were prepared and added onto the RNA sample followed by a $15-\mathrm{min}$ incubation at $42^{\circ} \mathrm{C}$ and 5-min incubation at $95^{\circ} \mathrm{C}$. The cDNA samples were later diluted as required.

Human epigenetic chromatin modification enzymes $R T^{2}$ profiler $^{T M}$ PCR array. The Human Epigenetic Chromatin Modification Enzyme RT ${ }^{2}$ Profiler $^{\mathrm{TM}}$ PCR Array (PAHS-085A) (SABiosciences) was used to detect the expression levels of 84 key genes listed in Table I.

A total of $2,300 \mu 1 \mathrm{RT}-\mathrm{PCR}$ array mix $(102 \mu \mathrm{l}$ diluted cDNA, 1,150 $\mu \mathrm{l} 2 \mathrm{X} \mathrm{RT}^{2}$ SYBR-Green ROX FAST master mix and 1,048 $\mu 1 \mathrm{H}_{2} \mathrm{O}$ ) was prepared and loaded into 96-well Human Epigenetic Chromatin Modification Enzymes RT ${ }^{2}$ Profiler $^{\mathrm{TM}}$ PCR Arrays $20 \mu \mathrm{l} /$ well. Arrays were placed in Rotor-Gene RG-3000 (Corbett Research, Qiagen, Germany) and were initially activated at $95^{\circ} \mathrm{C}$ for $10 \mathrm{~min}$ followed by 40 cycles of $95^{\circ} \mathrm{C}$ for $15 \mathrm{sec}$ and $60^{\circ} \mathrm{C}$ for $30 \mathrm{sec}$ incubation. Array data were analyzed and 8 genes were determined to be the most overexpressed or underexpressed, and crossvalidates using RT-qPCR.

$R T^{2} q P C R$ primer assay. The cDNA samples of the 8 genes selected to be overexpressed or underexpressed ( $A U R K B$, AURKA, SETD8, PAK1,NEK6, KDM4C, HDACl and HDAC7) and the housekeeping gene (HPRTl) were also examined by RT-qPCR. The primer assays and SYBR-Green master mix 
Table I. Histone modification genes to be investigated.

Histone modifications

DNA methyltransferase

Histone methyltransferase

Histone methyltransferase

SET domain proteins

(activation of histone methyltransferase)

Histone phosphorylation

Histone ubiquination

DNA/histone demethylase

Histone deacetylase
Genes
(SABiosciences) specific for the 8 genes were purchased and each PCR reaction mix was prepared by adding $12.5 \mu \mathrm{l}$ of SYBR-Green master mix and $1 \mu 1$ of primer $(10 \mathrm{pmol}) / 2.2 \mu 1$ cDNA sample. The total volume was adjusted to $25 \mu \mathrm{l}$ with $\mathrm{dH}_{2} \mathrm{O}$ and PCR mixes were loaded on the plate of Rotor-Gene RG-3000 (Corbett Research) for amplification. Amplification was performed with an initial denaturation step at $95^{\circ} \mathrm{C}$ for $5 \mathrm{~min}$ followed by 40 cycles of $94^{\circ} \mathrm{C}$ for $1 \mathrm{~min}, 61^{\circ} \mathrm{C}$ for $40 \mathrm{sec}$, and $72^{\circ} \mathrm{C}$ for $1 \mathrm{~min}$ with a final elongation step at $72^{\circ} \mathrm{C}$ for 2 min. Cycle threshold $(\mathrm{Ct})$ values obtained from the RT-qPCR reactions were normalized to the reference gene (HPRT1) and evaluated using REST 2009 (Relative Expression Software Tool V.2.0.13) in standard mode.

Data analysis. Data were analyzed using $\mathrm{RT}^{2}$ profiler PCR array and $\mathrm{RT}^{2} \mathrm{qPCR}$ primer assay data analysis software (http://www.sabiosciences.com/pcrarraydataanalysis.php). PCR array was quantified based on the $\mathrm{Ct}$ number. A gene was considered to be not detectable when $\mathrm{Ct}$ was $>32$. $\mathrm{Ct}$ was defined as 35 for the $\Delta \mathrm{Ct}$ calculation when the signal was under detectable limits. Fold-change and fold-regulation values $>2$ were indicative of upregulated genes, whereas the fold-change values $<0.5$ and fold-regulation values $<-2$ were indicative of downregulated genes.

Statistical analysis. Results were presented as the mean values \pm standard deviation and the p-values were calculated based on a Student's t-test of the replicate $2-\Delta \mathrm{Ct}$ values for each gene in the control, CRC and UC groups. $\mathrm{P}<0.05$ was considered to indicate a statistically significant result.

\section{Results}

Patients and histone modification gene expression analysis. Sixty patients were included in the study. They were divided into three groups, 20 patients in the CRC group (histo-
Table II. Histone modification gene expression analysis in CRC.

\begin{tabular}{llll}
\hline Histone gene & Fold-change & \multicolumn{1}{c}{$95 \% \mathrm{CI}$} & P-value \\
\hline AURKB & 7.3871 & $(1.54-13.23)$ & 0.00125 \\
AURKA & 6.9307 & $(1.48-12.38)$ & 0.00271 \\
SETD8 & 1.3491 & $(0.33-2.37)$ & 0.43853 \\
PAK1 & 6.4733 & $(1.01-11.94)$ & 0.00152 \\
NEK6 & 7.7355 & $(1.19-14.28)$ & 0.00090 \\
KDM4C & 0.6849 & $(0.17-1.20)$ & 0.11222 \\
HDAC1 & 7.4876 & $(1.33-13.65)$ & 0.00313 \\
HDAC7 & 8.0948 & $(1.39-14.80)$ & 0.00293 \\
HPRT1 & 0.9211 & $(0.69-1.16)$ & 0.58991 \\
\hline
\end{tabular}

CRC group was compared with the control group. CRC, colorectal cancer; CI, confidence interval.

pathologically confirmed), 20 patients in the UC group (histopathologically confirmed), and 20 patients in the control group (normal colon mucosa without any macroscopic and histopathologic finding of UC or CRC). The patients in the study group had a mean age of $57.80 \pm 12.3$ years. Mean ages in individual groups were $59.12 \pm 12.1,56.85 \pm 12.6$ and $57.45 \pm 11.5$ years in the CRC, UC and the control groups, respectively The three groups did not differ significantly with regards to age $(\mathrm{p}=0.284)$. The proportion of male gender in total was $51.7 \%(n=31)$. Gender distribution in the CRC, UC and control groups did not statistically differ (CRC M/F, 9/11; $\mathrm{UC} \mathrm{M} / \mathrm{F}, 11 / 9$; control M/F, 9/11; and p=0.339).

Sites of CRCs were assessed and the majority of the tumors were located in the distal colon. The proportion of the CRC patients by site of involvement were as follows: rectum, $35 \%$ $(n=7)$; sigmoid colon, $35 \%(n=7)$; descending colon, $5 \%(n=1)$; 


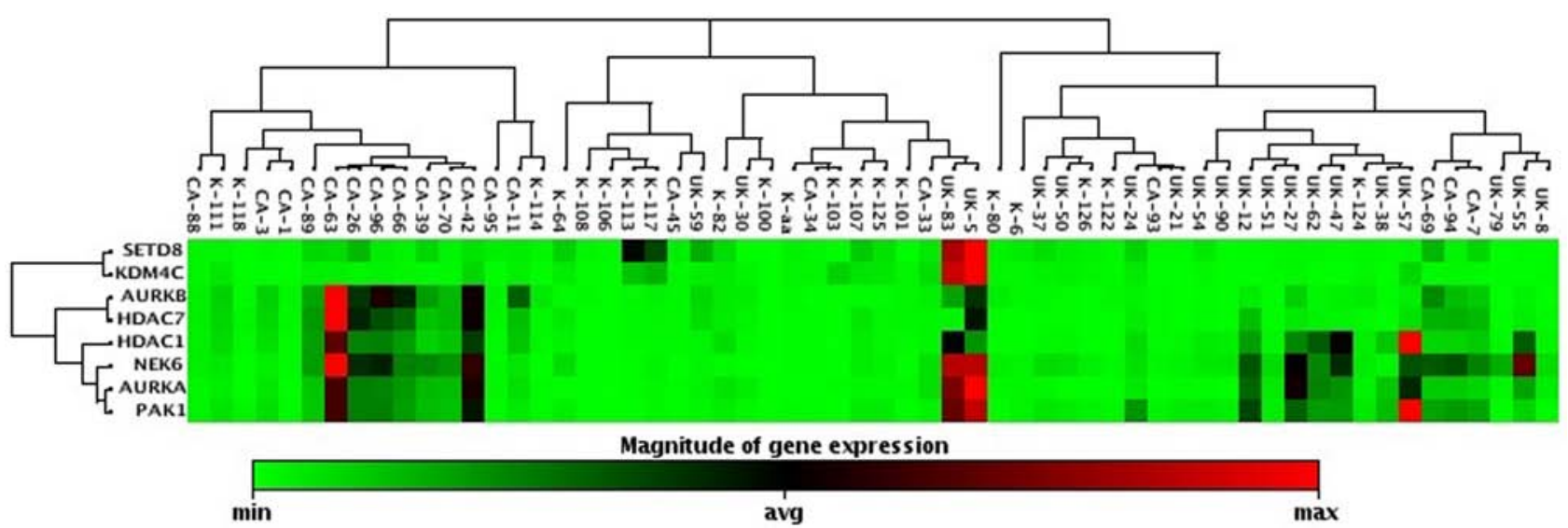

Figure 1. The clustergram creates a heat map with dendrograms to indicate that genes are co-regulated. The color saturation reflects the magnitude of the change in gene expression. Green squares denote lower gene expression in the experimental samples (ratios $<1)$, black squares denote genes equally expressed (ratios near 1), red squares show higher than control levels of gene expression (ratios $>1$ ), and gray squares indicate insufficient or missing data. The x-axis indicates the groups, and the y-axis indicates the genes. CRC, colorectal cancer; UC, ulcerative colitis; CTR, control group.

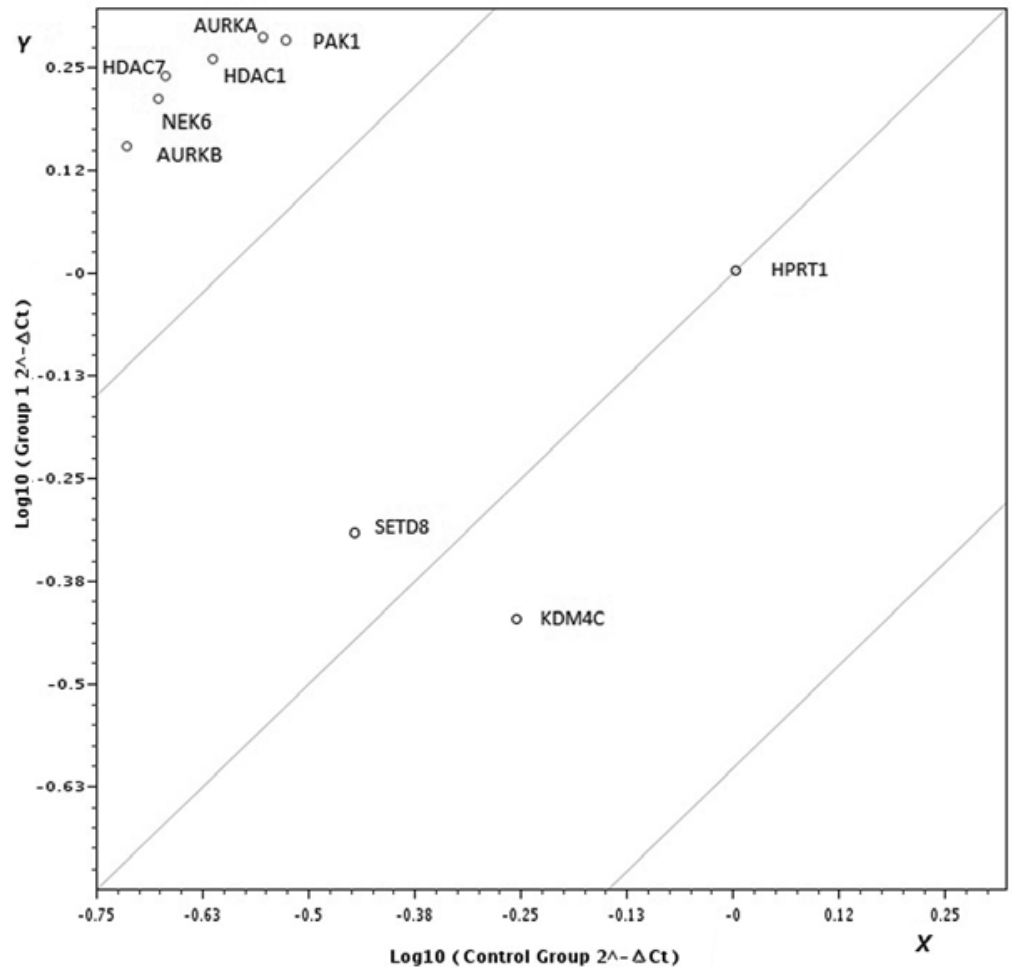

Figure 2. Overexpressed genes in CRC. Hybridization intensity of each gene in the CRC and control groups appears as a $\log 10$ base scattered plateau. The $\mathrm{x}$-axis represents the control group and the $\mathrm{y}$-axis represents the $\mathrm{CRC}$ group. $\mathrm{CRC}$, colorectal cancer.

transverse colon, $10 \%(\mathrm{n}=2)$; ascending colon, $10 \%(\mathrm{n}=2)$; and cecum, $5 \%(\mathrm{n}=1)$. Pathological diagnosis was adenocarcinoma for all the CRC patients. Of the patients, $25 \%(n=5)$ had poorly differentiated, $70 \%(n=14)$ had moderately differentiated tumors and only $5 \%(n=1)$ had well-differentiated tumors.

In CRC patients $(\mathrm{n}=20)$, overexpression of the $A U R K A$, $A U R K B, H D A C 1, H D A C 7, N E K 6$ and $P A K 1$ genes was statistically significantly higher compared to the control group (fold-change >2) (Figs. 1 and 2). CRC and control groups did not differ statistically significantly with regards to the expression of SETD8 or KDM4C genes (fold-change $<2, \mathrm{p}>0.05$ ) (Table II).
In $\mathrm{UC}(\mathrm{n}=20)$ patients, overexpression of the AURKA, HDAC1, NEK6 and $P A K 1$ genes was greater as compared to the control group (fold-change $>2$ ) (Figs. 1 and 3 ). The UC and control groups did not differ statistically significantly with regard to the expression of $A U R K B, H D A C 7, S E T D 8$ or $K D M 4 C$ genes (fold-change $<2, \mathrm{p}>0.05$ ) (Table III). The overexpression of the $A U R K B$ and $H D A C 7$ genes was statistically significantly higher in the CRC group compared to the UC group $(\mathrm{p}<0.05)$. The UC and CRC groups did not statistically differ significantly with regard to the overexpression of the AURKA,NEK6, PAKl and HDACl genes (Table IV). 


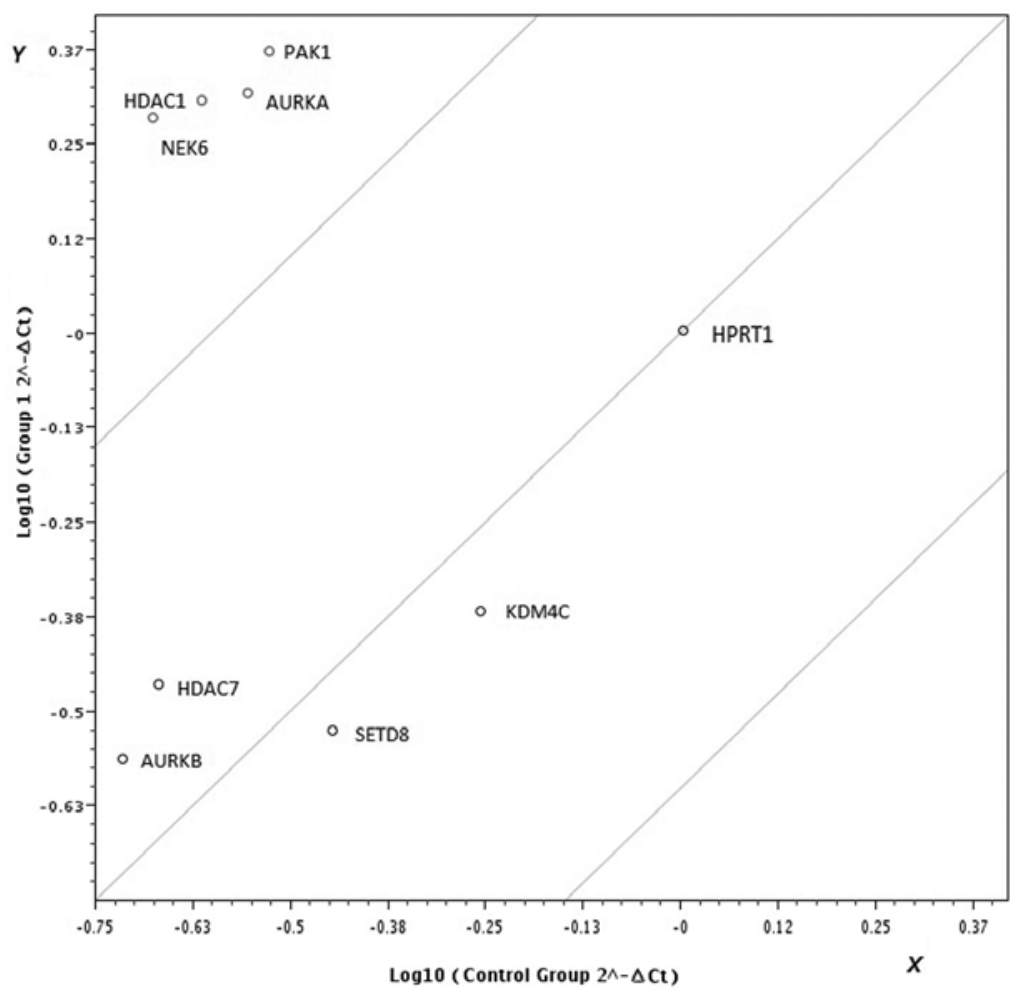

Figure 3. Overexpressed genes in UC. Hybridization intensity of each gene in the UC and control groups appears as a log 10 base scattered plateau. The x-axis shows the control group and the y-axis the UC group. UC, ulcerative colitis.

Table III. Histone modification gene expression analysis in UC.

\begin{tabular}{lcll}
\hline Histone gene & Fold-change & \multicolumn{1}{c}{$95 \% \mathrm{CI}$} & P-value \\
\hline AURKB & 1.4162 & $(0.36-2.47)$ & 0.16986 \\
AURKA & 7.4384 & $(1.02-13.85)$ & 0.00486 \\
SETD8 & 0.8322 & $(0.00-1.66)$ & 0.48752 \\
PAK1 & 7.953 & $(1.02-14.89)$ & 0.00542 \\
NEK6 & 9.161 & $(1.83-16.49)$ & 0.00107 \\
KDM4C & 0.7711 & $(0.00-1.54)$ & 0.26249 \\
HDAC1 & 8.3195 & $(1.19-15.45)$ & 0.00549 \\
HDAC7 & 1.5988 & $(0.36-2.84)$ & 0.20862 \\
HPRT1 & 0.9727 & $(0.72-1.23)$ & 0.96950 \\
\hline
\end{tabular}

UC group was compared with the control group. UC, ulcerative colitis; CI, confidence interval.

UC subgroup gene expression analyses

Gene expression analyses by colon involvement. The UC patients $(n=20)$ were subdivided into two subgroups by colonic involvement as follows: the patients with involvement that is proximal to the splenic flexure $(55 \%, \mathrm{n}=11)$ (extensive colitis or pancolitis), and left colon involvement including pouchitis, $(45 \%, \mathrm{n}=9)$. In the UC subgroup with extensive colitis or pancolitis, the overexpression of the NEK6 and AURKA genes was statistically significantly higher than that in the patients with left colon involvement (Fig. 4 and Table V).
Table IV. Comparison of the gene expression of the CRC and UC groups.

\begin{tabular}{lcrr}
\hline Histone gene & Fold-change & \multicolumn{1}{c}{$95 \% \mathrm{CI}$} & P-value \\
\hline AURKB & 5.2162 & $(0.46-9.97)$ & 0.00796 \\
AURKA & 0.9317 & $(0.00001-1.89)$ & 0.40211 \\
SETD8 & 1.6211 & $(0.22-3.02)$ & 0.26484 \\
PAK1 & 0.8139 & $(0.04-1.59)$ & 0.34676 \\
NEK6 & 0.8444 & $(0.02-1.67)$ & 0.79039 \\
KDM4C & 0.8882 & $(0.07-1.71)$ & 0.17068 \\
HDAC1 & 0.9 & $(0.06-1.74)$ & 0.46234 \\
HDAC7 & 5.063 & $(0.40-9.72)$ & 0.01954 \\
HPRT1 & 0.947 & $(0.69-1.21)$ & 0.64247
\end{tabular}

CRC group was compared with UC group. CRC, colorectal cancer; UC, ulcerative colitis; CI, confidence interval.

Gene expression analyses by disease duration. The patients diagnosed with UC were subdivided into two subgroups by disease duration as those with a disease duration of $\geq 10$ years $(60 \%, \mathrm{n}=12)$ and those a disease duration of $<10$ years $(40 \%$, $\mathrm{n}=8$ ). In patients with a disease duration of $\geq 10$ years, the overexpression of the NEK6,AURKA, PAK1 and HDAC1 genes was statistically significantly higher compared to those with a disease duration of $<10$ years (Fig. 5 and Table VI).

Gene expression analyses by disease severity. None of the UC patients had a history of treatment with an antitumor necrosis 


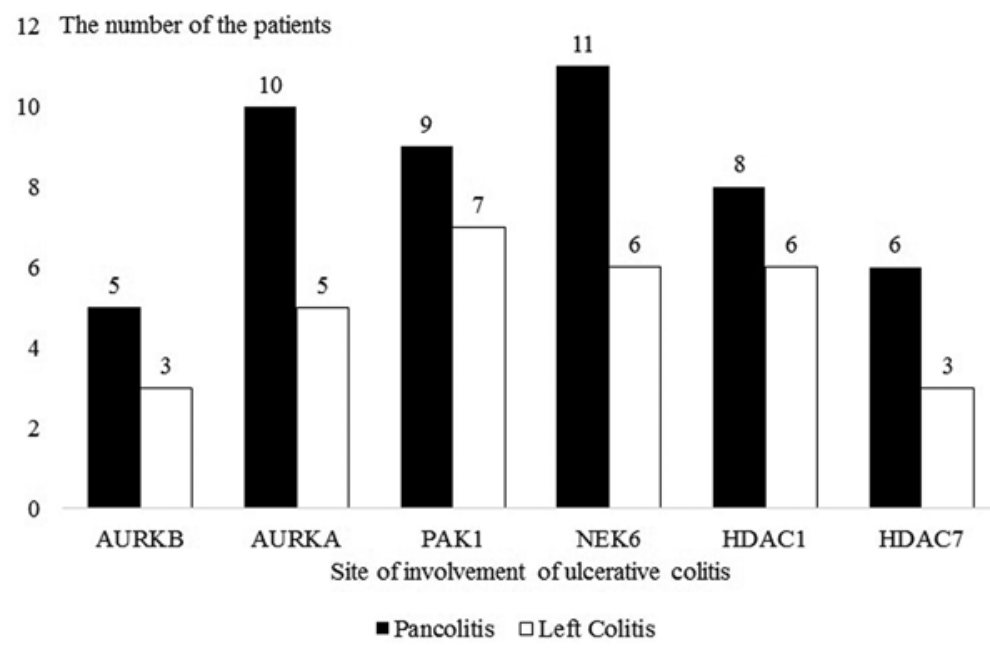

Figure 4. Overexpressed gene analysis of patients with disease involvement that is proximal to the splenic flexure (pancolitis-extensive colitis) and those with disease involvement in the left colon.

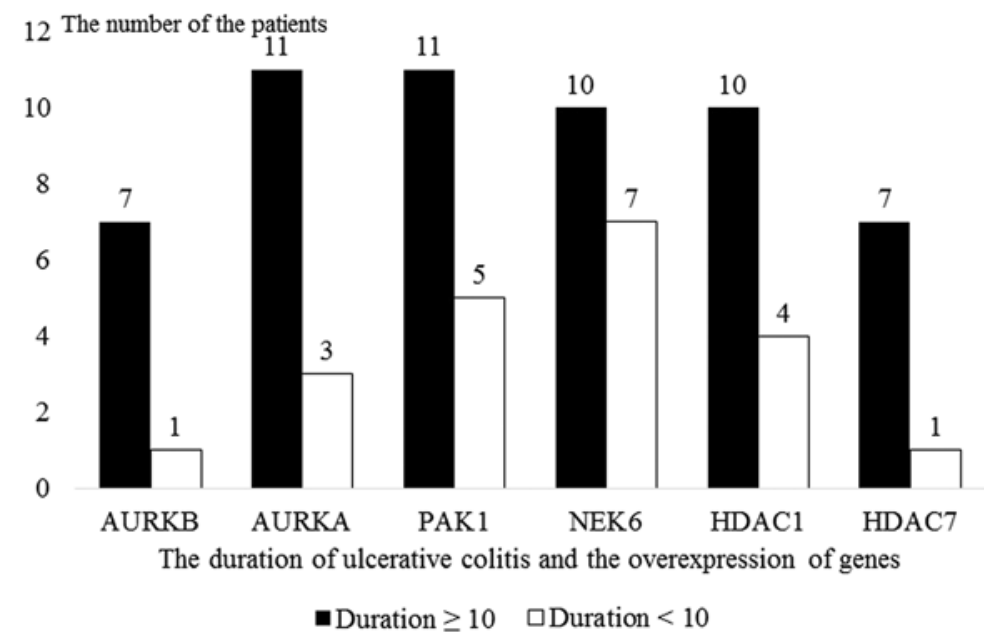

Figure 5. Overexpressed gene analysis of UC patients with a disease duration of $\geq 10$ and $<10$ years. UC, ulcerative colitis.

factor (anti-TNF) drug, a calcineurin inhibitor such as cyclosporin and immunomodulator agents such as azathiopurine and mycophenolate mofetil. The UC patients were on oral and/or rectal 5-ASA treatment. The UC patients were divided into two subgroups by the medications used during periods of exacerbation and remission as an indicator of disease behavior as follows: patients who received steroid treatment for remission induction and azathioprine for remission maintenance $(55 \%, \mathrm{n}=11)$ and those who received only 5 -ASA $(45 \%, \mathrm{n}=9)$. The two subgroups did not differ statistically significantly with regards to gene expression (Fig. 6 and Table VII).

\section{Discussion}

Chronic inflammation has a significant role in many types of cancer including Helicobacter pylori-associated gastric cancer, hepatitis $\mathrm{C}$-associated hepatocellular cancer and colitis-associated CRC (20). Development of inflammation associated with cancer is characterized by the gradual accrual
Table V. Gene expression analysis by colon involvement in UC.

\begin{tabular}{lclc}
\hline Histone gene & Fold-change & \multicolumn{1}{c}{$95 \% \mathrm{CI}$} & P-value \\
\hline AURKB & 1.3494 & $(0.00001-2.95)$ & 0.24876 \\
AURKA & 5.3678 & $(0.00001-12.55)$ & 0.02699 \\
SETD 8 & 0.7484 & $(0.00001-1.88)$ & 0.31268 \\
PAK1 & 2.2402 & $(0.00001-5.16)$ & 0.06460 \\
NEK6 & 6.7131 & $(0.00001-13.96)$ & 0.01489 \\
KDM4C & 1.1199 & $(0.00001-2.85)$ & 0.21034 \\
HDAC1 & 3.1064 & $(0.00001-7.06)$ & 0.14044 \\
HDAC7 & 2.0928 & $(0.00001-4.59)$ & 0.26969 \\
HPRT1 & 1 & $(1.00-1.00)$ & - \\
\hline
\end{tabular}

Patients with disease involvement proximal to the splenic flexure (pancolitis-extensive colitis) and those with disease involvement in the left colon, which is more distal to the splenic flexure were compared. UC, ulcerative colitis; CI, confidence interval. 


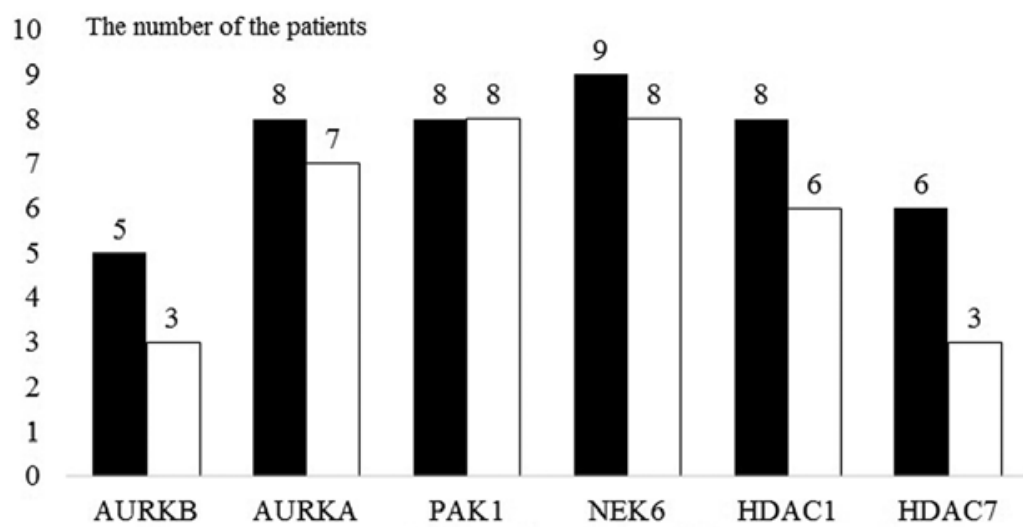

The current treatment of ulcerative colitis and the overexpression of genes

- 5-ASA + AZA + Steroid $\quad$ Only 5-ASA

Figure 6. Overexpressed gene analysis of UC patients treated with AZA + steroid + ASA vs. ASA only. UC, ulcerative colitis.

Table VI. Gene expression analysis by disease duration in UC.

\begin{tabular}{lccc}
\hline Histone gene & Fold-change & $95 \% \mathrm{CI}$ & P-value \\
\hline AURKB & 5.8903 & $(0.01-11.77)$ & 0.165124 \\
AURKA & 14.1641 & $(0.43-27.90)$ & 0.012857 \\
SETD8 & 2.2211 & $(0.00001-5.51)$ & 0.284641 \\
PAK1 & 10.1085 & $(1.15-19.06)$ & 0.015182 \\
NEK6 & 3.388 & $(0.00001-7.06)$ & 0.013988 \\
KDM4C & 3.1032 & $(0.00001-7.46)$ & 0.223753 \\
HDAC1 & 8.959 & $(1.39-16.53)$ & 0.013921 \\
HDAC7 & 4.2673 & $(0.00001-8.67)$ & 0.231647 \\
HPRT1 & 1 & $(1.00-1.00)$ & - \\
\hline
\end{tabular}

Patients with a disease duration of $\geq 10$ years and $<10$ years were compared. UC, ulcerative colitis; CI, confidence interval.

of genetic and epigenetic alterations in several proto-oncogene and tumor-suppressor genes (20). Understanding of the epigenetic changes in cancer cells has led to gaining insight on the stages of carcinogenesis. It has been shown that epigenetic changes has similar effects as genetic changes on the stages of carcinogenesis and that they trigger carcinogenesis (21). As our knowledge on cancer molecular biology expands monitoring of precancerous and cancerous stages improves $(22,23)$. The fact that epigenetic changes, unlike genetic ones, are reversible supports the hypothesis that epigenetic treatments may be used in the future (24).

In the present study, NEK6 and AURKA genes in particular were overexpressed in the patients with UC and CRC, supporting our hypothesis that the two genes are of value as diagnostic and prognostic biomarkers in UC and CRC patients. $H D A C 1, H D A C 7, P A K 1$ and $A U R K B$ genes were significantly more overexpressed in CRC patients compared to the controls. Additionally, $H D A C l$ and $P A K 1$ genes were more overex-
Table VII. Gene expression analysis by treatments received by patients in $\mathrm{UC}$.

\begin{tabular}{llrr}
\hline Histone gene & Fold-change & $95 \% \mathrm{CI}$ & P-value \\
\hline AURKB & 0.4597 & $(0.00001-1.01)$ & 0.24561 \\
AURKA & 0.3842 & $(0.00001-0.97)$ & 0.23059 \\
SETD8 & 0.2455 & $(0.00001-0.58)$ & 0.14288 \\
PAK1 & 0.2564 & $(0.00001-0.58)$ & 0.06694 \\
NEK6 & 0.698 & $(0.00001-1.67)$ & 0.73757 \\
KDM4C & 0.3124 & $(0.00001-0.77)$ & 0.17477 \\
HDAC1 & 0.4711 & $(0.00001-1.12)$ & 0.42449 \\
HDAC7 & 0.5182 & $(0.00001-1.12)$ & 0.23014 \\
HPRT1 & 1 & $(1.00-1.00)$ & -
\end{tabular}

UC patients treated with AZA + steroid + ASA were compared with those who were treated with ASA only. UC, ulcerative colitis; CI, confidence interval.

pressed in UC patients compared to the controls. The NEK6 and $A U R K A$ genes are involved in the epigenetic mechanisms of the formation of most of the gastrointestinal cancers. Although dysplasia was not detected in any of the UC patients there were no differences between NEK6 and AURKA gene expression in UC and CRC patients. There was a significant overexpression in the $H D A C 7$ and $A U R K B$ genes compared between the UC and CRC groups.

p-21 activated kinase (PAK1) coordinates RAS/RAF/ MAPK and Wnt/ $\beta$-catenin signaling in the initiation and progression of CRC carcinogenesis by acting on the flow of small GTPases (25-27). Dammann et al demonstrated that PAK1 has an important role in the carcinogenesis of colitis-associated CRC and suggested that it may be a therapeutic target with potential use in chemoprevention (28). Similarly, an experimental model by He et al (18) demonstrated that 5-ASA normalized the increased membranous expression of the adhesion molecules E-cadherin and $\beta$-catenin in the 
carcinogenesis of CRC. The authors also reported that 5-ASA suppressed PAK1 expression and neoplastic progression in the carcinogenesis of CRC (17). In the stages of colitis-associated carcinogenesis, intestinal PAK1 expression increased in the presence of inflammation and malignant transformation. PAK1 was involved in the carcinogenesis of colitis-associated CRC by maintaining the colaboration of mitogen-activated kinase, phosphoinositide 3-kinase (PI3K/AKT), nuclear factor $\kappa \mathrm{B}(\mathrm{NF}-\mathrm{\kappa B})$ and $\mathrm{Wnt} / \beta$-catenin pathways and ensuring continuance of these pathways (28).

Histone deacetylase 1 (HDAC1) controls cell proliferation, differentiation, migration and apoptosis by suppressing p21 and p27 cyclin-dependent kinase (CDK) (29). HDAC1 is involved in the carcinogenesis stages of numerous GIS cancers including CRC, and HDAC1 overexpression is associated with tumor differentiation, increased proliferation, increased invasion, advanced disease and poor prognosis $(12,14,30$ 34). Turgeon et al demonstrated that HDAC1 regulated the proliferation and differentiation of the intestinal and colonic epithelium in the inflammatory response (35). It has also been shown that inflammation and tumor formation may be suppressed in experimental colitis and inflammation-induced tumorigenesis models owing to the antiproliferative properties of HDAC inhibitors (16).

The members of the aurora kinase family (AURKA, AURKB and AURKC) are serine/threonine kinases involved as key regulators in mitosis. AURKA regulates the G2/M phase of the cell cycle by acting on the regulation of centrosome functions, spindle montage (linkage), chromosome separation and cytokinesis. AURKA mRNA is amplified in numerous types of cancers including CRC (36-38). A study evaluating $386 \mathrm{CRC}$ subjects found that a high AURKA expression was associated with increased recurrence/relapse frequency and suggested that AURKA may be used as a prognostic marker (15). AURKA is overexpressed in inflamed esophagitis tissue with precancerous lesion in esophageal adenocarcinoma (39) and in Barrett's esophagus secondary to chronic irritation/inflammation (40), suggesting that it is involved in the carcinogenesis associated with inflammation. A study by Katsha et al, investigated the role of AURKA in the tumorigenesis of inflammation-associated gastric cancer, compared healthy stomach tissue with premalignant and malignant lesions and found higher levels of AURKA protein and nuclear NF- $\kappa B$ levels (41). The authors described that AURKA overexpression initiated and maintained NF- $\mathrm{KB}$ and tumorigenesis activation in a chronic inflammatory process. The authors also suggested that AURKA inhibitors may be developed as therapeutic agents for gastric cancer (41).

NEK6 is a serine/threonine kinase from the never in mitosis gene A (NIMA)-related kinase 6 family involved in mitotic division (42). Termination of mitosis, chromatin spindle defects and abnormal chromosome differentiation have been observed and apoptosis was triggered with NEK6 dysfunction (43-45). Nassirpour et al demonstrated that the kinase activity of NEK6 was increased in several malignant human cancer cells including breast, uterus, colon, stomach, ovary, lung, kidney, rectum, thyroid, cervix, prostate, pancreas and small intestine cancers, and that suppression of NEK6 resulted in tumor regression in a mice xenograft model (19). A study by Kasap et al demonstrated that the NEK6 gene was overexpressed in tissues with esophagitis to a similar extent as esophageal adenocarcinomas, and that the extent of NEK6 gene overexpression increased proportionally with the increasing severity of esophagitis (39).

To the best of our knowledge, this is the first study to show that the NEK6, AURKA, PAKI and HDACl genes were significantly elevated in human UC tissues. In light of the results reported from the studies mentioned above and those obtained in the present study, it was identified that the NEK6 and AURKA genes, in particular, as well as the $P A K 1$ and $H D A C l$ genes play a significant role in the stages of UC-associated CRC, and that they have a prognostic relevance in CRC. Additionally, the four histone modification enzyme genes can be used in anticancer treatments as therapeutic targets. Of note, these results were identified despite the absence of dysplasia in the subjects with UC. This finding suggests that the four genes are involved in the early stages of inflammation-associated carcinogenesis during which dysplasia did not occur. The four genes, particularly NEK6 and AURKA, can be used as early markers in the development of CRC in UC patients.

The absence of a significant difference in NEK6 and AURKA gene expression between the UC and CRC patient groups, as determined in the present study, can be considered to reflect the predisposition of UC patients to CRC.

The risk of developing CRC in UC increases proportionally to the duration of disease, early age of disease onset, the extent of colonic involvement, inflammation severity and presence of primary sclerosing cholangitis (3-6). The present results have demonstrated that the NEK6, AURKA, PAK1 and HDACl genes were significantly more overexpressed with an increasing $\mathrm{UC}$ disease duration, a risk factor for $\mathrm{CRC}$, in patients diagnosed with UC. In a meta-analysis of 116 individual studies by Eaden $e t$ al, the cumulative CRC risk in UC patients was $2 \%$ after 10 years, $8 \%$ after 20 years and $18 \%$ after 30 years, and the study thus recommended colonoscopic screening for CRC risk after 8 years for patients with pancolitis and after 12 years for those with left colitis (1). Based on these data, detection of these genes can be of additional benefit to colonoscopic screening in UC. The present study did not identify a link between the NEK6, AURKA, PAKl and HDACl genes and inflammation severity. This indicates that the epigenetic changes involved in CRC stages with long-standing chronic inflammation occur to a greater extent with time regardless of the inflammation severity. Consistent with the results of the study by Kasap et al (39) comparing the histone modification profiles in esophageal adenocarcinoma and esophagitis tissues, the AURKA and NEK6 genes were more overexpressed in UC patients with diffuse colon involvement, whereas PAK1 and HDAC1 overexpression was independent of the extent of disease involvement. While this may be due to the inadequate number of subjects, it can also be explained by the chemoprevention induced by 5 -ASA, which was received by all UC patients in the present study, or by the active presence of PAK1 and HDACl in the stages of inflammation that precede the occurrence of carcinogenesis $(16,17,35)$.

In conclusion, the results show that the overexpression particularly of the AURKA and NEK6 genes in patients with UC and CRC in the Turkish population. Clarification of the molecular pathophysiology of CRC and UC contributes to the treatment and prognosis of the diseases. Future studies are 
needed to understand the roles of the four genes in the carcinogenesis associated with colitis. Thus, NEK6 and AURKA can be considered promising genetic markers.

\section{Acknowledgements}

This study was supported by the Celal Bayar University Coordinator of the Scientific Research Projects (2013-09) Manisa, Turkey.

\section{References}

1. Eaden JA, Abrams KR and Mayberry JF: The risk of colorectal cancer in ulcerative colitis: A meta-analysis. Gut 48: 526-535, 2001.

2. Ekbom A, Helmick C, Zack M and Adami HO: Ulcerative colitis and colorectal cancer. A population-based study. N Engl J Med 323: 1228-1233, 1990 .

3. Claessen MM, Lutgens MW, van Buuren HR, Oldenburg B, Stokkers PC, van der Woude CJ, Hommes DW, de Jong DJ, Dijkstra G, van Bodegraven AA, et al: More right-sided IBD-associated colorectal cancer in patients with primary sclerosing cholangitis. Inflamm Bowel Dis 15: 1331-1336, 2009.

4. Gillen CD, Walmsley RS, Prior P, Andrews HA and Allan RN: Ulcerative colitis and Crohn's disease: A comparison of the colorectal cancer risk in extensive colitis. Gut 35: 1590-1592, 1994.

5. Rutter M, Saunders B, Wilkinson K, Rumbles S, Schofield G, Kamm M, Williams C, Price A, Talbot I and Forbes A: Severity of inflammation is a risk factor for colorectal neoplasia in ulcerative colitis. Gastroenterology 126: 451-459, 2004.

6. Winther KV, Jess T, Langholz E, Munkholm P and Binder V: Long-term risk of cancer in ulcerative colitis: A populationbased cohort study from Copenhagen County. Clin Gastroenterol Hepatol 2: 1088-1095, 2004.

7. Kulaylat MN and Dayton MT: Ulcerative colitis and cancer. J Surg Oncol 101: 706-712, 2010.

8. Rhodes JM and Campbell BJ: Inflammation and colorectal cancer: IBD-associated and sporadic cancer compared. Trends Mol Med 8: 10-16, 2002.

9. Jawad N, Direkze N and Leedham SJ: Inflammatory bowel disease and colon cancer. Recent Results Cancer Res 185: 99-115, 2011.

10. Migheli F and Migliore L: Epigenetics of colorectal cancer. Clin Genet 81: 312-318, 2012.

11. Stypula-Cyrus Y, Damania D, Kunte DP, Cruz MD Subramanian H, Roy HK and Backman V: HDAC up-regulation in early colon field carcinogenesis is involved in cell tumorigenicity through regulation of chromatin structure. PLoS One 8: e64600, 2013

12. Higashijima J, Kurita N, Miyatani T, Yoshikawa K, Morimoto S, Nishioka M, Iwata T and Shimada M: Expression of histone deacetylase 1 and metastasis-associated protein 1 as prognostic factors in colon cancer. Oncol Rep 26: 343-348, 2011.

13. Wilson AJ, Byun DS, Popova N, Murray LB, L'Italien K, Sowa Y, Arango D, Velcich A, Augenlicht LH and Mariadason JM: Histone deacetylase 3 (HDAC3) and other class I HDACs regulate colon cell maturation and p21 expression and are deregulated in human colon cancer. J Biol Chem 281: 13548-13558, 2006.

14. Witt O, Deubzer HE, Milde T and Oehme I: HDAC family: What are the cancer relevant targets? Cancer Lett 277: 8-21, 2009.

15. Belt EJ, Brosens RP, Delis-van Diemen PM, Bril H, Tijssen M, van Essen DF, Heymans MW, Beliën JA, Stockmann HB, Meijer S, et al: Cell cycle proteins predict recurrence in stage II and III colon cancer. Ann Surg Oncol 19 (Suppl 3): S682-S692, 2012.

16. Glauben R, Sonnenberg E, Zeitz M and Siegmund B: HDAC inhibitors in models of inflammation-related tumorigenesis. Cancer Lett 280: 154-159, 2009.

17. Khare V, Lyakhovich A, Dammann K, Lang M, Borgmann M, Tichy B, Pospisilova S, Luciani G, Campregher C, Evstatiev R, et al: Mesalamine modulates intercellular adhesion through inhibition of p-21 activated kinase-1. Biochem Pharmacol 85 234-244, 2013

18. He H, Huynh N, Liu KH, Malcontenti-Wilson C, Zhu J, Christophi C, Shulkes A and Baldwin GS: P-21 activated kinase knockdown inhibits $\beta$-catenin signalling and blocks colorectal cancer growth. Cancer Lett 317: 65-71, 2012.
19. Nassirpour R, Shao L, Flanagan P, Abrams T, Jallal B, Smeal T and Yin MJ: Nek6 mediates human cancer cell transformation and is a potential cancer therapeutic target. Mol Cancer Res 8: 717-728, 2010

20. Chiba T, Marusawa H and Ushijima T: Inflammation-associated cancer development in digestive organs: Mechanisms and roles for genetic and epigenetic modulation. Gastroenterology 143: $550-563,2012$

21. Feinberg AP, Ohlsson R and Henikoff S: The epigenetic progenitor origin of human cancer. Nat Rev Genet 7: 21-33, 2006.

22. Lao VV and Grady WM: Epigenetics and colorectal cancer. Nat Rev Gastroenterol Hepatol 8: 686-700, 2011.

23. Yi JM, Dhir M, Guzzetta AA, Iacobuzio-Donahue CA, Heo K, Yang KM, Suzuki H, Toyota M, Kim HM and Ahuja N: DNA methylation biomarker candidates for early detection of colon cancer. Tumour Biol 33: 363-372, 2012.

24. Yoo CB and Jones PA: Epigenetic therapy of cancer: Past, present and future. Nat Rev Drug Discov 5: 37-50, 2006

25. He TC, Sparks AB, Rago C, Hermeking H, Zawel L, da Costa LT, Morin PJ, Vogelstein B and Kinzler KW: Identification of c-MYC as a target of the APC pathway. Science 281: 1509-1512, 1998.

26. Polakis P: The many ways of Wnt in cancer. Curr Opin Genet Dev 17: 45-51,2007.

27. Vogelstein B, Fearon ER, Hamilton SR, Kern SE, Preisinger AC, Leppert M, Nakamura Y, White R, Smits AM and Bos JL: Genetic alterations during colorectal-tumor development. N Engl J Med 319: 525-532, 1988

28. Dammann K, Khare V and Gasche C: Tracing PAKs from GI inflammation to cancer. Gut 63: 1173-1184, 2014

29. Lagger G, O'Carroll D, Rembold M, Khier H, Tischler J, Weitzer G, Schuettengruber B, Hauser C, Brunmeir R, Jenuwein $\mathrm{T}$, et al: Essential function of histone deacetylase 1 in proliferation control and CDK inhibitor repression. EMBO J 21: 2672-2681, 2002.

30. Choi JH, Kwon HJ, Yoon BI, Kim JH, Han SU, Joo HJ and Kim DY: Expression profile of histone deacetylase 1 in gastric cancer tissues. Jpn J Cancer Res 92: 1300-1304, 2001.

31. Miyake K, Yoshizumi T, Imura S, Sugimoto K, Batmunkh E, Kanemura H, Morine $\mathrm{Y}$ and Shimada M: Expression of hypoxia-inducible factor-1alpha, histone deacetylase 1 , and metastasis-associated protein 1 in pancreatic carcinoma: Correlation with poor prognosis with possible regulation. Pancreas 36: e1-e9, 2008.

32. Weichert W, Röske A, Gekeler V, Beckers T, Ebert MP, Pross M, Dietel M, Denkert C and Röcken C: Association of patterns of class I histone deacetylase expression with patient prognosis in gastric cancer: A retrospective analysis. Lancet Oncol 9: 139-148, 2008.

33. Weichert W, Röske A, Gekeler V, Beckers T, Stephan C, Jung K, Fritzsche FR, Niesporek S, Denkert C, Dietel M, et al: Histone deacetylases 1,2 and 3 are highly expressed in prostate cancer and HDAC2 expression is associated with shorter PSA relapse time after radical prostatectomy. Br J Cancer 98: 604-610, 2008.

34. Weichert W, Röske A, Niesporek S, Noske A, Buckendahl AC, Dietel M, Gekeler V, Boehm M, Beckers T and Denkert C: Class I histone deacetylase expression has independent prognostic impact in human colorectal cancer: Specific role of class I histone deacetylases in vitro and in vivo. Clin Cancer Res 14: $1669-1677,2008$

35. Turgeon N, Blais M, Gagné JM, Tardif V, Boudreau F, Perreault N and Asselin C: HDAC1 and HDAC2 restrain the intestinal inflammatory response by regulating intestinal epithelial cell differentiation. PLoS One 8: e73785, 2013.

36. Marumoto T, Zhang D and Saya H: Aurora-A - a guardian of poles. Nat Rev Cancer 5: 42-50, 2005.

37. Bischoff JR, Anderson L, Zhu Y, Mossie K, Ng L, Souza B, Schryver B, Flanagan P, Clairvoyant F, Ginther C, et al: A homologue of Drosophila aurora kinase is oncogenic and amplified in human colorectal cancers. EMBO J 17: 3052-3065, 1998.

38. Carvalho B, Postma C, Mongera S, Hopmans E, Diskin S, van de Wiel MA, van Criekinge $W$, Thas $O$, Matthäi A, Cuesta MA, et al: Multiple putative oncogenes at the chromosome $20 \mathrm{q}$ amplicon contribute to colorectal adenoma to carcinoma progression. Gut 58: 79-89, 2009.

39. Kasap E, Boyacioglu SO, Korkmaz M, Yuksel ES, Unsal B, Kahraman E, Ozütemiz O and Yuceyar H: Aurora kinase A (AURKA) and never in mitosis gene A-related kinase 6 (NEK6) genes are upregulated in erosive esophagitis and esophageal adenocarcinoma. Exp Ther Med 4: 33-42, 2012. 
40. Rugge M, Fassan M, Zaninotto G, Pizzi M, Giacomelli L, Battaglia G, Rizzetto C, Parente P and Ancona E: Aurora kinase A in Barrett's carcinogenesis. Hum Pathol 41: 1380-1386, 2010.

41. Katsha A, Soutto M, Sehdev V, Peng D, Washington MK, Piazuelo MB, Tantawy MN, Manning HC, Lu P, Shyr Y, et al Aurora kinase A promotes inflammation and tumorigenesis in mice and human gastric neoplasia. Gastroenterology 145: 1312-1322.e1-8, 2013.

42. Jee HJ, Kim AJ, Song N, Kim HJ, Kim M, Koh H and Yun J: Nek6 overexpression antagonizes p53-induced senescence in human cancer cells. Cell Cycle 9: 4703-4710, 2010.
43. Belham C, Roig J, Caldwell JA, Aoyama Y, Kemp BE, Comb M and Avruch J: A mitotic cascade of NIMA family kinases. Nercc1/Nek9 activates the Nek6 and Nek7 kinases. J Biol Chem 278: 34897-34909, 2003.

44. O'Regan L and Fry AM: The Nek6 and Nek7 protein kinases are required for robust mitotic spindle formation and cytokinesis. Mol Cell Biol 29: 3975-3990, 2009.

45. Cao X, Xia Y, Yang J, Jiang J, Chen L, Ni R, Li L and Gu Z: Clinical and biological significance of never in mitosis gene A-related kinase 6 (NEK6) expression in hepatic cell cancer. Pathol Oncol Res 18: 201-207, 2012. 